\title{
Employment Protection and Business Cycles in Emerging Economies
}

\author{
Ruy Lama* Carlos Urrutia** \\ * International Monetary Fund \\ ** Centro de Investigación Económica, ITAM
}

\author{
DT. N ${ }^{\circ} 2012-003$ \\ Serie de Documentos de Trabajo \\ Working Paper series \\ Enero 2012
}

Los puntos de vista expresados en este documento de trabajo corresponden a los autores y no reflejan necesariamente la posición del Banco Central de Reserva del Perú.

The views expressed in this paper are those of the authors and do not reflect necessarily the position of the Central Reserve Bank of Peru. 


\section{Employment Protection and Business Cycles in Emerging Economies ${ }^{\dagger}$}

\author{
Ruy Lama \\ International Monetary Fund
}

Carlos Urrutia

Centro de Investigación Económica,

December 2011

\section{ABSTRACT}

We build a small open economy, real business cycle model with labor market frictions to evaluate the role of employment protection in shaping business cycles in emerging economies. The model features matching frictions and an endogenous selection effect by which inefficient jobs are destroyed in recessions. In a quantitative version of the model calibrated to the Mexican economy we find that reducing separation costs to a level consistent with developed economies would reduce output volatility by 15 percent. We also use the model to analyze the Mexican crisis episode of 2008 and conclude that an economy with lower separation costs would have experienced a smaller drop in output and in measured total factor productivity with no significant change in aggregate employment.

\footnotetext{
†We would like to thank Felipe Meza, Sangeeta Pratap, and Jorge Roldós for their useful comments. We also receive great feedback while presenting this paper in seminars at the IMF, ITAM, and the Banco Central de Reserva del Perú. The paper was partly written while Carlos Urrutia was visiting the IMF Institute. The views expressed herein are those of the authors and should not be attributed to the IMF, its Executive Board, or its management. The support of CONACYT through research grant No. 81825 is thankfully acknowledged. All errors are our own. Contact Information: rlama@imf.org, currutia@itam.mx.
} 


\section{Introduction}

Business cycles in emerging economies are more volatile than in developed countries. There are two leading approaches to account for this fact. On the one hand, Aguiar and Gopinath (2007) argue that differences in the shock process to trend in productivity can explain the higher volatility of output and consumption in emerging economies. On the other hand, Neumeyer and Perri (2005) and Mendoza (2010) argue that business cycles in emerging economies are amplified by financial frictions and changes in the access to international credit markets.

Both explanations, however, overlook one important difference between developed and emerging economies: The work of labor markets. Table 1 shows that emerging economies face more restrictive labor regulations, measured as a larger number of weeks of wages paid by firms in the event of a separation, and less employment volatility relative to output. ${ }^{1}$ One implication of an excessive labor regulation is that it limits the process of adjustment of employment in response to shocks. Moreover, the lack of flexibility of labor markets also mitigates the natural process of selection of firms in the economy, generating potentially large misallocation of resources.

We develop a small open economy model with labor matching frictions and evaluate the role of labor market regulation in shaping business cycles in emerging economies. Key to our story is a selection effect by which the most inefficient jobs are destroyed in recessions. By reducing the volatility of labor flows, employment protection mitigates the selection effect and its cleansing impact. This basic mechanism allows us to connect labor market regulations and the volatilities of measured total factor productivity (TFP), output and employment. We explicitly check the predictions of each of these three variables with the data. ${ }^{2}$

\footnotetext{
${ }^{1}$ The Heckman and Pages indicator (H\&P) measures the costs of advance notice and compulsory severance payments expressed in present value, assuming up to 20 years of tenure. Also, the World Bank publishes as part of the Doing Business Indicators a measure of the monetary costs in terms of weeks of severance payments due for firing a worker, averaged across workers of 1,5 , and 10 years of tenure. We report both indicators as they capture different dimensions of employment protection.

${ }^{2}$ It is unclear whether the benchmark business cycles models for emerging economies are consistent with some basic facts about the labor market adjustment. As shown in Fernandez and Meza (2011), Aguiar and Gopinath's calibration imply a countercyclical labor input in emerging economies, contrary to the data. In Neumeyer and Perri (2005), on the other hand, the excess volatility in output for emerging economies depends on the labor input being more volatile. However, relative to output, employment is less volatile in emerging economies compared to developing countries (see Table 1).
} 


\begin{tabular}{|l|cc|c|c|}
\hline & $\begin{array}{c}\sigma(y) \\
(\text { percent })\end{array}$ & $\sigma(l) / \sigma(y)$ & \multicolumn{2}{|c|}{ Employment Protection } \\
\cline { 3 - 4 } & & & DBI (weeks) & HEP $($ weeks $)$ \\
\hline Emerging Economies & 4.19 & 0.59 & 23 & 12 \\
Argentina & 1.76 & 0.62 & 9 & 7 \\
Brazil & 1.79 & 0.62 & 12 & 14 \\
Chile & 1.74 & 0.88 & 19 & 14 \\
Colombia & 2.17 & 0.53 & 22 & 13 \\
Mexico & $\mathbf{2 . 3 3}$ & $\mathbf{0 . 6 5}$ & $\mathbf{1 7}$ & $\mathbf{1 2}$ \\
Average & & & & \\
\hline Developed Economies & 1.10 & 1.08 & 8 & 2 \\
Australia & 1.28 & 0.67 & 5 & 4 \\
Canada & 1.35 & 0.66 & 0 & 1 \\
Norway & 1.39 & 0.92 & 0 & 6 \\
New Zealand & 1.15 & 0.89 & 3 & $\mathbf{3}$ \\
United Kingdom & $\mathbf{1 . 2 5}$ & $\mathbf{0 . 8 4}$ & $\mathbf{3}$ & 19 \\
Average & & & & \\
\hline
\end{tabular}

Sources: GDP and employment from Haver Analytics. Quarterly samples start at 1987 except in: Argentina (1991), Brazil (1990), Colombia (1994) and Norway (1989); all samples end in 2007. Indices of Employment Protection from Doing Business Indicators (2010) and Heckman and Pages (2000).

Table 1: Business Cycle Properties and Employment Protection Across Countries

There are two technologies in the economy. One produces intermediate inputs using only labor and the other produces a final good using intermediate inputs and capital. The final good technology is subject to an exogenous aggregate productivity shock. For intermediate inputs, there is a continuum of jobs or matches between one firm and one worker. Each job is indexed by an idiosyncratic labor efficiency which evolves randomly over time. Firms post vacancies each period to hire new workers. As in Mortensen and Pissarides (1994), a matching function determines the probability of filling a vacancy as a function of the overall labor market tightness in the economy. Employment protection is introduced as a fixed cost of breaking an existing match, i.e., a separation or firing cost. We focus initially on the efficient solution in order to abstract from inefficiencies coming out of the wage determination mechanism and congestion externalities.

After observing the shocks at the beginning of the period, the planner can decide to destroy a job if the labor efficiency is too low. The optimal separation rule implies an endogenous threshold level depending on the aggregate state of the economy, such that the 
planner destroys jobs with labor efficiency below that level. The most inefficient jobs are then destroyed in recessions, increasing the average productivity of the remaining matches. Recessions have a cleansing effect reflected on the volatility of the aggregate productivity of the economy. With larger firing costs, the same initial drop on the exogenous aggregate productivity component would lead to fewer separations and therefore a bigger fall in measured TFP.

We calibrate the model to Mexico, which has been used as a benchmark emerging economy by Aguiar and Gopinath (2007), among others. In particular, the separation cost is calibrated in order to match the observed volatility of aggregate employment relative to output. We obtain large separation costs which amount to an aggregate loss of resources of about 1.7 percent of GDP. By construction, the baseline model is consistent with a set of business cycle moments in Mexico, although it over-predicts the correlation between employment and output.

Our calibrated model allows us to perform counterfactual experiments. To illustrate the impact of greater flexibility in labor markets we consider an alternative economy with lower separation costs, broadly consistent with the level of employment protection in Canada. This alternative economy would feature less output and measured TFP volatility than the baseline. According to the experiment, separation costs are responsible for about one-third of the excess volatility in output in Mexico with respect to Canada. As expected, firing costs also reduce the volatility of labor flows.

We also analyze a particular episode, the Great Recession of 2008, through the lens of our theory. In Mexico the downturn was particularly sharp, exhibiting a 8.9 percent drop in GDP below trend. TFP was responsible for most of the drop in output, while employment fell much less. We calibrate the sequence of exogenous aggregate productivity shocks in order to reproduce, using the baseline model, the evolution of GDP during this episode. We then perform the counterfactual experiment of reducing separation costs. We find that an economy similar to Mexico but with the level of employment protection in Canada would have experienced a drop in output of 7.6 percent, 1.3 percentage points less than in the baseline case.

We borrow from an extensive literature which incorporates labor matching friction 
to a standard, closed economy, real business cycle model, including the seminal works by Merz (1995) and Andolfatto (1996). These papers focus though on developed economies and include neither endogenous separations nor a selection mechanism like ours. Lagos (2006) explicitly analyzes the connection between labor market policies, selection of firms, and measured TFP. However, his focus is on steady state levels, not on short-run fluctuations. In this sense we relate more to the work of Veracierto (2007), who analyzes business cycle fluctuations with endogenous selection and conclude that, in the presence of congestion externalities, labor market policies dampen the response of the economy to aggregate shocks. ${ }^{3}$ We abstract from congestion externalities and focus on a different set of policies, namely separation costs. Also, compared with Lagos (2006) and Veracierto (2007), we treat aggregation of heterogeneous matches in a different, much simpler framework.

Other related work includes Boz, Durdu and Li (2009), who also analyze labor matching frictions in a small open emerging economy. However, while these authors add a wage determination mechanism to study the volatility of earnings, we abstract from wage setting and focus instead on the selection effect. Also, we introduce separation costs and use these institutional features to distinguish between emerging and developed economies. Christiano et al. (2010) estimate a model combining financial and labor market frictions for the Swedish economy and find this interaction is able to reproduce the business cycle facts of this small open economy without resorting to investment shocks or wage markup shocks. Finally, our work contributes also to the vast literature which tries to explain the labor wedge, that is, the ratio between the marginal rate of substitution of consumption for leisure and the marginal product of labor. The labor wedge is used as a diagnostic tool to identify the presence of frictions or distortions in the labor market. ${ }^{4}$

The paper is organized as follows. Section 2 describes the model, highlights the main mechanism and provides some supporting evidence. Section 3 discusses the calibration and the business cycle properties of the baseline economy. Section 4 analyzes the role of sep-

\footnotetext{
${ }^{3}$ Following a similar approach, Den Haan et. al. (2000) show how the combination of endogenous job destruction and capital adjustment costs increases significantly the persistence of productivity shocks in the Mortensen and Pissarides framework.

${ }^{4}$ For a discussion on the labor wedge see Shimer (2009). The empirical investigation in Lama (2011) shows that the labor wedge is a relevant factor behind episodes of output drops in Latin America, highlighting the importance of labor market frictions to account for the business cycle in emerging economies.
} 
aration costs in business cycle moments. The 2008 crisis episode is analyzed in Section 5. Section 6 concludes.

\section{A Small Open Economy with Labor Market Frictions}

We introduce a one-sector, small open economy model with labor market frictions. The model captures the type of matching frictions in Mortensen and Pissarides (1994) and includes as an institutional constraint a cost to destroy an ongoing work relationship. Establishments producing intermediate goods are heterogeneous in productivity, which follows an i.i.d. stochastic process. Together with an endogenous exit rule, this implies that aggregate TFP is endogenous and depends on the institutional constraints imposed on the environment.

We will focus on a constrained efficient allocation obtained solving a social planner's problem. By focusing on the efficient allocation we abstract from wage determination and congestion externalities. Merz (1995) and Andolfatto (1996) provide examples of the standard decentralization using Nash bargaining. Veracierto (2007) discusses possible decentralizations of this efficient outcome which are not based on repeated bargaining.

\subsection{The Constrained Efficient Allocation}

Preferences A benevolent social planner chooses the sequence of consumption and labor supply to maximize the expected discounted lifetime utility function:

$$
E_{0} \sum_{t=0}^{\infty} \beta^{t} \frac{\left[C_{t}-\varphi \frac{L_{t}^{1+\nu}}{1+\nu}\right]^{1-\sigma}}{1-\sigma}
$$

where $C_{t}$ represents consumption and $L_{t}$ the mass of workers in the representative family. The parameter $\sigma$ represents the intertemporal elasticity of substitution. This utility function is non-separable in consumption and leisure, as in Greenwood, Hercowitz, and Hoffman (1988). ${ }^{5}$ The parameter $\varphi$ governs the disutility of labor and $\nu$ is the inverse of the Frisch elasticity

\footnotetext{
${ }^{5}$ This utility function, also known as GHH, has been used extensively in small open economy models to mitigate the impact of wealth effects on labor supply. It can also be interpreted as a reduced form of a more general model of home production, as shown in Benhabib et al. (1991). This is particularly relevant for emerging economies in which self-employment and the informal sector are important.
} 
of labor supply. Families have a constant endowment of labor $\bar{L}$ each period. Individuals who do not work are unemployed, and their mass is denoted by $U_{t} \equiv \bar{L}-L_{t}$. We abstract from individuals not participating in the labor force.

Technologies There are two technologies in the economy. One to produce intermediate inputs using only labor, and one to produce a final good, using intermediate inputs and capital.

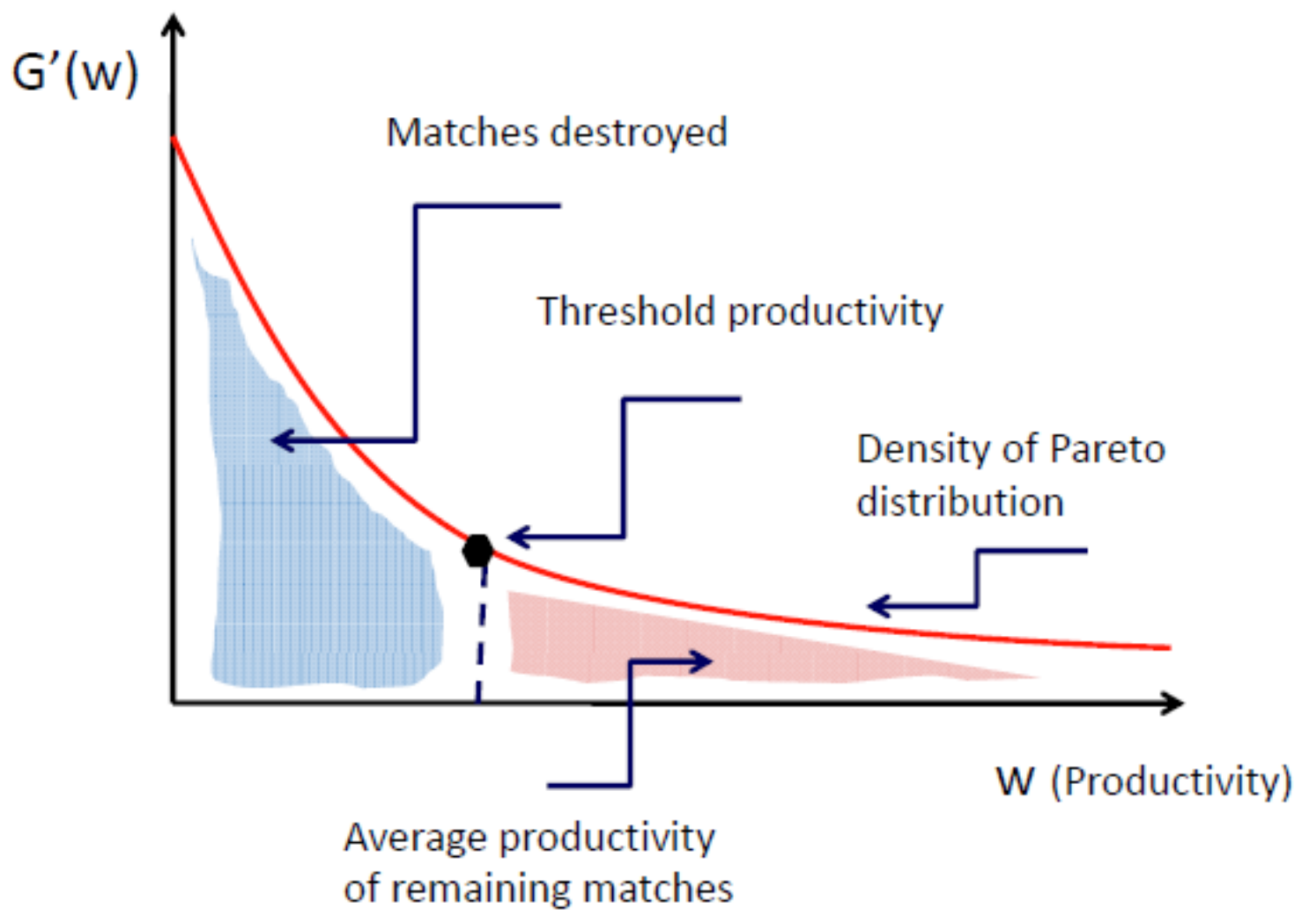

Figure1: Optimal Separation Rule and Endogenous Productivity Threshold

For intermediate inputs, there is a continuum of jobs or matches between one firm and one worker. Workers are identical, but jobs are indexed by a labor efficiency shock $\omega$ so that each job produces $\omega$ units of output. The idiosyncratic labor efficiency is a random variable independently distributed over time with distribution function $G$. After observing the shocks at the beginning of the period, the planner can decide to destroy a job if the labor efficiency is too low. The optimal separation rule discussed in the Appendix implies an endogenous 
threshold level $\hat{\omega}_{t}$ depending on the aggregate state of the economy, such that the planner destroys jobs with labor efficiency below it (see Figure 1). Using the law of large numbers, the output of the intermediate sector is

$$
M_{t}=\left[\frac{\Gamma\left(\hat{\omega}_{t}\right)}{1-G\left(\hat{\omega}_{t}\right)}\right] L_{t},
$$

with $\Gamma(x)=\int_{\omega \geq x} \omega d G(\omega)$. In the quantitative experiment we use a Pareto distribution for the idiosyncratic productivity shocks, with

$$
G(\omega)=1-\left(\frac{\bar{\omega}}{\omega}\right)^{\sigma_{\omega}}
$$

Intermediate inputs and capital are combined to produce a final good using a constant returns to scale technology:

$$
Y_{t}=A_{t}\left(K_{t}\right)^{\alpha}\left(M_{t}\right)^{1-\alpha}
$$

where $A_{t}$ is an aggregate shock to the productivity of the final good sector. Notice that we can write the aggregate production function of the economy as

$$
\underbrace{Y_{t}}_{G D P}=\underbrace{\left[A_{t}\left(\frac{\Gamma\left(\hat{\omega}_{t}\right)}{1-G\left(\hat{\omega}_{t}\right)}\right)^{1-\alpha}\right]}_{T F P}\left(K_{t}\right)^{\alpha}\left(L_{t}\right)^{1-\alpha}
$$

where the term in brackets represents measured TFP and includes both an exogenous $\left(A_{t}\right)$ and an endogenous component.

Labor flows and frictions The dynamics of employment are given by the following law of motion:

$$
L_{t}=L_{t-1}+H_{t}-S_{t}
$$

where $H_{t}$ represents new hirings (job creation) and $S_{t}$, separations (or job destruction) at time $t$. Similarly, hirings and separations deplete or feed the pool of unemployed workers. Departing from a model of instantaneous labor adjustment, we introduce matching frictions and separation costs. 
In order to assign an unemployed worker to a job, the planner must first create a vacancy or employment opportunity. Creating a vacancy has a (small) cost $\eta$ in units of the final good. Hirings are given by a well defined matching function, depending on the number of vacancies posted by the planner $\left(V_{t}\right)$ and the current number of unemployed workers in the economy, $U_{t}$ :

$$
H_{t}=D\left(U_{t}\right)^{\theta}\left(V_{t}\right)^{1-\theta}
$$

The coefficient $D$ indicates the efficiency at which the matching process is conducted. ${ }^{6}$

After hirings take place, the planner shreds some jobs due to a low productivity realization. Total separations are equal to

$$
S_{t}=G\left(\hat{\omega}_{t}\right)\left[L_{t-1}+H_{t}\right]
$$

We introduce a separation $\operatorname{cost} \kappa$ in units of the final good. This cost represents deadweight losses incurred by the planner when breaking an existing match.

Feasibility The final good $Y_{t}$ is allocated for the purchases of consumption $C_{t}$, investment $I_{t}$, net exports $N X_{t}$ and the payment of vacancy and separation costs: ${ }^{7}$

$$
Y_{t}=C_{t}+I_{t}+N X_{t}+\eta V_{t}+\kappa S_{t}
$$

The capital stock evolves according to the following law of motion:

$$
K_{t+1}=(1-\delta) K_{t}+I_{t}-\frac{\vartheta}{2}\left(\frac{I_{t}}{K_{t}}-\delta\right)^{2} K_{t}
$$

\footnotetext{
${ }^{6}$ The assumption of a matching function with constant returns to scale generate endogenous probabilities for the transition from employment to unemployment $p_{t}$, and from unfilled vacancies to filled ones $q_{t}$ :

$$
p_{t}=\frac{H_{t}}{U_{t}}=D\left(\frac{V_{t}}{U_{t}}\right)^{1-\theta} \quad q_{t}=\frac{H_{t}}{V_{t}}=D\left(\frac{U_{t}}{V_{t}}\right)^{\theta}
$$

These probabilities depend on the labor market tightness coefficient $\frac{V_{t}}{U_{t}}$. More vacancies posted relative to the pool of unemployed workers raises the probability $p_{t}$ of employing a currently unemployed worker, but reduces the probability $q_{t}$ of filling a vacancy.

${ }^{7}$ We also constructed an alternative version of the model in which hiring and separation costs are rebated to the planner as a lump sum transfer. The results were quantitatively very similar, so we omit them from the paper.
} 
where $\delta$ is the depreciation rate. We introduce a quadratic adjustment cost of capital in order to match the volatility of investment observed in the data. As shown in SchmittGrohé (1998), without adjustment costs, the standard small open economy model generates unrealistic values for the standard deviation of investment.

The total labor force is allocated to work or to the unemployed pool:

$$
L_{t}+U_{t}=\bar{L}
$$

Finally, the stock of foreign debt of the domestic economy (minus net foreign asset position) evolves according to:

$$
B_{t+1}=\left(1+r_{t}^{*}\right) B_{t}-N X_{t}
$$

Also, the effective interest rate is

$$
\left(1+r_{t}^{*}\right)=\left(1+i_{t}^{*}\right) \Theta\left(B_{t}\right)
$$

where $i_{t}^{*}$ is the foreign interest rate and $\Theta\left(B_{t}\right)$ is an endogenous risk premium, which has a very small elasticity with respect to the net foreign asset position to ensure stationarity in the model (see Schmitt-Grohé and Uribe, 2003).

Exogenous shocks The social planner faces two aggregate shocks: An exogenous productivity shock and an external shock to interest rates. We assume the following $A R(1)$ processes:

$$
\begin{aligned}
\log \left(A_{t}\right) & =\rho_{A} \log \left(A_{t-1}\right)+\varepsilon_{t}^{A}, \\
\log \left(1+i_{t}^{*}\right) & =\rho_{i} \log \left(1+i_{t-1}^{*}\right)+\left(1-\rho_{i}\right) \log \left(1+i^{*}\right)+\varepsilon_{t}^{i},
\end{aligned}
$$

where the disturbances $\varepsilon_{t}$ are .i.i.d. with mean zero, variances $\sigma_{A}^{2}$ and $\sigma_{i}^{2}$, respectively, and covariance $\sigma_{A, i}$.

The planner maximizes expected lifetime utility (1) subject to constraints (2) - (12). The resulting allocations represent the constrained efficient outcome for this economy, constrained by the set of labor allocation frictions and exogenous shocks imposed on the planner. 


\subsection{Selection and the Cleansing Effect of Recessions}

Before moving to a quantitative version of the model it is useful to underline the main mechanisms at play and discuss some supporting evidence. Expansion and recessions in the model would be driven by exogenous aggregate productivity shocks $\left(A_{t}\right)$ and by foreign interest rate shocks $\left(i_{t}^{*}\right)$. A negative productivity shock would reduce the social value of keeping a job, leading the planner to break some existing matches. Our particular choice of preferences ensures that aggregate employment falls in a recession. The subsequent fall in consumption is mitigated by the desire of the planner to smooth consumption over time, which would be reflected in a large drop in investment and a worsening of the current account.

So far, this is the standard story behind small open economy real business cycle models. Our model introduces a new selection mechanism. In a recession, the planner would not choose randomly which jobs to close, but follow an endogenous exit rule in which matches with the lowest idiosyncratic productivity are destroyed first. Hence, the more jobs are destroyed, the higher the average productivity of the remaining matches. Recessions have a cleansing effect that mitigates to some extent the initial negative productivity shock on measured TFP.

Table 2 provides some support for this mechanism using Mexican labor market data obtained from ENEU household's survey. ${ }^{8}$ We divide individuals in four occupational status: Employed, Self-Employed, Unemployed, and Out of the Labor Force, and compute quarterly transition matrices between these four categories. Also, for individuals who were either employed or self-employed in one quarter we compute the average hourly wage ratio in that quarter between those who changed categories to unemployed or out of labor force in the following quarter and those who remained in their original category. We call this variable the selection effect; if less than one, it means that workers who lose their jobs are selected from the bottom of the productivity distribution inside the category, measuring productivity by their wages previous to the change in occupational status.

In Table 2 we report a few of the transitions estimated and their corresponding selection

${ }^{8}$ ENEU (Encuesta Nacional de Empleo Urbano) is a rotating panel of workers in urban areas. It includes both formal and informal workers. This data set has been used extensively to doument labor market facts for Mexico. See, for instance, the studies of Pratap and Quintin (2010) and Bosch and Maloney (2009). We are very grateful to Sangeeta Pratap for giving us access to a cleaned version of this dataset. 


\begin{tabular}{|c|c|c|c|c|}
\hline \multirow{2}{*}{} & \multicolumn{2}{|c|}{ Employed $\rightarrow$ Unemployed } & \multicolumn{2}{c|}{ Self-Employed $\rightarrow$ Unemployed } \\
\cline { 2 - 5 } & percent & selection & percent & selection \\
\hline $1988-99$ & 1.67 & 0.74 & 0.90 & 0.93 \\
1995 & 2.76 & 0.68 & 1.68 & 0.88 \\
\hline
\end{tabular}

\begin{tabular}{|c|c|c|c|c|}
\hline & \multicolumn{2}{|c|}{ Employed $\rightarrow$ Out Labor Force } & \multicolumn{2}{c|}{ Self-Employed $\rightarrow$ Out Labor Force } \\
\cline { 2 - 5 } & percent & selection & percent & selection \\
\hline $1988-99$ & 7.06 & 0.32 & 10.31 & 0.41 \\
1995 & 7.48 & 0.30 & 9.91 & 0.41 \\
\hline
\end{tabular}

Source: Own elaboration using Encuesta Nacional de Empleo Urbano (ENEU), sample from 1988:Q1 to 1999:Q4.

Table 2: Transitions between Occupational Status and Selection Effect in Mexico

variables. We average these indicators for the whole available sample (1988-1999) and also for the recession year of 1995. For example, averaging the whole sample, 1.67 percent of all employed workers in one quarter were unemployed in the following quarter and, on average, the hourly wage of those workers losing their employed status was 26 percent lower than those who remained employed. ${ }^{9}$ The overall table is consistent with: (i) separations being higher during recessions; (ii) a selection effect in which workers at the bottom of the wage (productivity) distribution are more likely to lose their jobs; and (iii) the selection effect being stronger during recessions. This is exactly the mechanism that we explore in our model.

\footnotetext{
${ }^{9}$ The transition rate from employment to unemployment is not a good measure of the separation rate for Mexico. It underestimates the level of turnover since it ignores transitions between jobs inside a quarter and movements out of the labor force.
} 


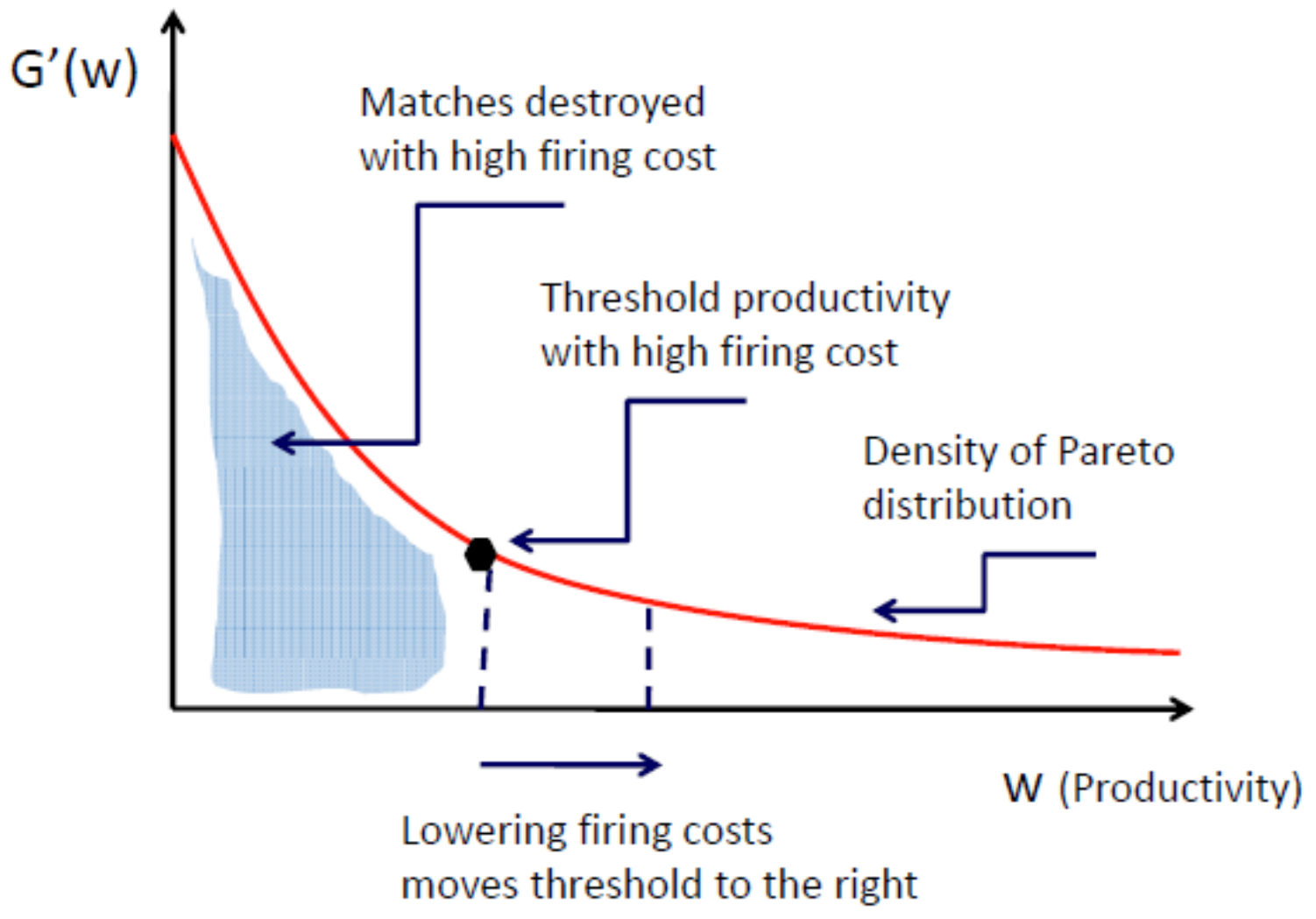

Figure 2: Optimal Separation Rule with High and Low Firing Costs

Separation costs play an important role due to this selection effect. In the model, higher firing costs imply that breaking a match is costlier, therefore reducing separations in a recession. But fewer separations also means that more inefficient matches remain active, dampening the selection effect and its cleansing impact (see Figure 2). With higher separations costs, the same initial drop in exogenous aggregate productivity component would lead to a bigger fall in measured TFP.

Notice, finally, that separation costs also have an impact on the planner's hiring decision. By reducing the social value of a worker, higher firing costs also imply fewer vacancies posted and fewer jobs created. The net effect of separation costs on employment is, therefore, ambiguous.

In the following sections we use a calibrated version of the model to quantify these mechanisms and evaluate their importance in explaining business cycles in emerging economies. 


\section{The Baseline Economy}

\subsection{Solution Method and Calibration}

To evaluate the quantitative predictions of the model we log-linearize the equations around the steady state. To ensure stationarity of the model, we introduce a risk premium term that depends on the net foreign asset position (see Schmitt-Grohé and Uribe, 2003). We use the algorithm proposed by Schmitt-Grohé and Uribe (2004) to solve the rational expectations model, which provides an efficient implementation of the solution method proposed by Blanchard and Kahn (1980).

The model is calibrated to match some features of the Mexican data, as an example of a small and fairly open emerging economy. One important feature of our calibration strategy is that instead of relying on imperfect measures of employment protection for Mexico we deduce the value of the firing cost from the business cycle properties of the model, in particular, the volatilities of employment and output.

Table 3 summarizes the calibration results. Each period is equivalent to one quarter. A few parameters have a direct empirical counterpart. The discount factor implies an annual real interest rate of 4 percent, and the depreciation rate is set to 5 percent per year. We take other parameters from the literature and perform sensitivity analysis with respect to some of their values at the end of Section 5. In the baseline case we use a capital share of one-third, a risk aversion coefficient of one, and a persistence of the exogenous aggregate productivity shock of 0.95 , as it is standard in the RBC literature. We chose a curvature of leisure in the utility function consistent with a Frisch elasticity of labor supply of $2.65 .{ }^{10}$ The elasticity of the matching function is taken from the study of Blanchard and Diamond (1989) for the US. Finally, we use the same curvature of the Pareto distribution for idiosyncratic productivity shocks as in Lagos (2006), and a hiring cost of 0.1 taken from Zhang (2008). ${ }^{11}$

\footnotetext{
${ }^{10}$ There is a large literature on estimating the elasticity of labor supply. This literature distinguishes between the micro elasticity and the macro elasticity, finding larger value for the latter. For instance, using the response of aggregate labor supply to changes in taxes, Rogerson and Wallenius (2007) obtain a macro elasticity of labor supply between 2.3 and 3 for the US. We choose the midpoint of this range for our experiment and perform sensitivity analysis on this parameter at the end of Section 5.

${ }^{11}$ This hiring cost is calibrated to a small open economy, and it has the same order of magnitude as in Shimer (2005). At the steady state the firing cost implies a loss of resources of less than 0.1 percent of GDP.
} 


\begin{tabular}{|l|c|c|}
\hline Parameter From Outside the Model & Symbol & Value \\
\hline Discount Factor & $\beta$ & 0.99 \\
World average Interest Rate & $i^{*}$ & $1 / \beta-1$ \\
Depreciation Rate & $\delta$ & $1.25 \%$ \\
Capital Share & $\alpha$ & 0.3 \\
Curvature Pareto Distribution & $\sigma_{\omega}$ & 1.5 \\
Persistence of Exogenous Productivity Shock & $\rho_{A}$ & 0.95 \\
Frisch Elasticity of Labor Supply & $1 / \nu$ & 2.65 \\
Elasticity of Matching Function & $\theta$ & 0.40 \\
Hiring Cost & $\eta$ & 0.1 \\
\hline Calibrated to Steady State Statistics & & \\
Disutility of Labor & $\varphi$ & 6.39 \\
Efficiency of Matching Function & $D$ & 0.67 \\
Scale of Pareto Distribution & $\bar{\omega}$ & 0.99 \\
\hline Estimated from EMBI Data for Mexico & & \\
S.D. of World Interest Rate & $\sigma_{i}$ & $1.37 \%$ \\
Persistence of World Interest Rate & $\rho_{i}$ & 0.96 \\
\hline Calibrated to Business Cycle Volatilities & & \\
S.D. of Exogenous Productivity Shock & $\sigma_{A}$ & $1.14 \%$ \\
Covariance Interest Rate and Productivity Shocks & $\sigma_{A, i}$ & -0.038 \\
Firing Cost & $\kappa$ & 3.90 \\
Adjustment Cost of Capital & $\vartheta$ & 65 \\
\hline
\end{tabular}

Table 3: Parameters for the Baseline Economy 
A second set of parameters is jointly calibrated so that the deterministic steady state of the model reproduces some key labor market statistics in Mexico. The disutility of labor parameter $\varphi$, the efficiency of the matching process $D$ and the scale of the Pareto distribution for idiosyncratic productivity shocks $\bar{\omega}$ are pinned down by an unemployment rate of 5 percent, a quarterly separation rate of 4 percent and a probability for filling a vacancy of 0.7 in a quarter. ${ }^{12}$ In all the experiments that follow we recalibrate the values of these three parameters so that the steady state of the model remains consistent with the three calibration targets.

Finally, a third set of parameters including the firing cost is jointly calibrated so that the business cycle properties of the model are consistent with the Mexican data. We first estimate the $A R(1)$ process for the interest rate that Mexico faces in international markets, using the EMBI as the empirical counterpart, as in Neumeyer and Perri (2005). Then, we jointly calibrate the firing cost $\kappa$, the standard deviation of the exogenous productivity shock $\sigma_{A}$, the covariance between productivity and interest rate shocks $\sigma_{A, i}$, and the adjustment cost of capital $\vartheta$ to match the observed volatilities of GDP and employment, the correlation between interest rates and output, and the volatility of investment. The details are explained in the next subsection.

\subsection{Business Cycle Properties}

The first column in Table 4 reports several business cycle statistics for the Mexican economy computed using a set of twenty year HP-filtered quarterly time series (1987:Q1 - 2007:Q3). The second column shows a similar set of statistics computed from data simulated from the baseline model. We solve the model using log-linearization techniques and perform a large number of simulations to compute average statistics.

The baseline model reproduces by construction the volatilities of GDP, investment, and aggregate employment. In particular, the model reproduces the relative fluctuations of employment with respect to GDP. For this, we required a firing cost of $\kappa \approx 4$, which

\footnotetext{
${ }^{12}$ The unemployment rate corresponds to an average adjusted rate for Mexico. The separation rate is consistent with an annual rate of job destruction of 15 percent, as estimated for Mexico in Kaplan et al. (2005).
} 


\begin{tabular}{|l|c|c|c|}
\hline & Data Mexico & Baseline Model & No $i^{*}$ shock \\
\hline$\sigma(y)$ & 2.17 & 2.17 & 2.21 \\
$\sigma(l) / \sigma(y)$ & 0.53 & 0.54 & 0.52 \\
$\sigma(i) / \sigma(y)$ & 3.34 & 3.37 & 1.29 \\
\hline $\operatorname{Corr}\left(1+i^{*}, y\right)$ & -0.16 & -0.17 & - \\
$\sigma(c) / \sigma(y)$ & 1.15 & 1.46 & 0.89 \\
$\operatorname{Corr}(n x / y, y)$ & -0.78 & -0.14 & 0.80 \\
\hline$\sigma(t f p)$ & 1.98 & 1.36 & 1.41 \\
$\operatorname{Corr}(t f p, y)$ & 0.93 & 0.99 & 0.99 \\
$\operatorname{Corr}(l, y)$ & 0.40 & 0.99 & 0.99 \\
$\sigma(l w e d g e)$ & 2.11 & 0.59 & 0.62 \\
Corr $($ lwedge, $y)$ & -0.73 & -0.96 & -0.98 \\
\hline
\end{tabular}

Table 4: Business Cycle Statistics: Data and Model

corresponds in the steady state equilibrium to a fraction of resources lost of about 1.7 percent of GDP. This seems a large number unless we take a broad view of all the costs incurred in breaking a work relation, including red tape, time cost, and so on. This is the view that we take in this paper.

The baseline model is also calibrated to reproduce the observed, negative correlation between interest rates and output in Mexico. Countercyclical interest rates are a key feature of emerging economies, as discussed by Neumeyer and Perri (2005). We impose this feature of the data into our model by assuming a negative correlation between interest rates and the exogenous component of TFP. This helps us to match qualitatively two important business cycles properties of emerging economies: A relative volatility of consumption to output greater than one, and a countercyclical trade balance. Turning off interest rate shocks in our model overturns these results (see the last column of the table).

The volatility of measured TFP is mitigated in the model by the endogenous selection mechanism, by which inefficient matches are destroyed in recessions. Everything else constant, the destruction of inefficient matches increases TFP, which partially compensates any contraction of exogenous productivity during recessions. A limitation with this mechanism is that procyclicality of employment is too high in the model, while in the data the correlation of employment and output is less than half. We still obtain a highly procyclical TFP, as in the data, but less volatile.

In order to measure the degree of inefficiency in the labor market, we define the labor 
wedge as the ratio of the marginal rate of substitution between leisure and consumption and the marginal product of labor:

$$
\text { lwedge } \equiv \frac{-U_{l}\left(C_{t}, L_{t}\right) / U_{c}\left(C_{t}, L_{t}\right)}{\alpha Y_{t} / L_{t}}
$$

Following Chari, Kehoe, and McGrattan (2007), the labor wedge can be interpreted as (one plus) the subsidy to employment required in order to satisfy the consumption/leisure first order condition in an otherwise frictionless labor market. An increase in the labor wedge would then represent an increase in the degree of labor market distortions. In our model, the labor wedge is endogenous and summarizes the frictions introduced by the search technology and institutional features, as the separation costs. As observed in Table 4, the labor wedge implied by our model is strongly countercyclical, since firing costs imply that the incidence of labor market distortions is larger in recessions. The same property is observed in the labor wedge computed from Mexican data, although its observed volatility is much larger.

\section{Separation Costs and Business Cycles}

We now analyze the impact of reducing separation costs on business cycles moments. In all the experiments, the starting point is the baseline economy calibrated to the Mexican data. The main experiment is to reduce the firing costs to one-fourth of its original level. Looking again at Table 1, this is a rough measure of the differences in employment protection between Mexico and Canada as measured by the size of severance payments. We recalibrate the steady state parameters in order to be consistent with the same initial steady state as in the baseline economy.

\subsection{Impulse Response Functions}

Figure 3 shows the response of the model to a 1 percent decrease in the exogenous productivity component. We compute the impulse response function for the baseline and an alternative economy with lower firing costs, calculated as one-fourth of its original level. Notice that measured TFP increases by less than 1 percent point in both cases. As explained 
before, the combination of firing costs and the selection effect dampens the effect of exogenous productivity on TFP. As shown in panel (b), the higher the separation cost, the larger the fall in measured TFP.

Panels (c) and (d) show the responses of GDP and employment. Consistent with the data, GDP is more sensitive to productivity innovations than employment. In spite of having GHH preferences, which suppresses the wealth effects, employment is less responsive to productivity since the firing costs and labor market search process makes it costly to adjust instantaneously the amount of labor in equilibrium. This can be seen in panels (e) and (f), reporting the response of hirings and separations separately. Higher firing costs make both hirings and separations less responsive to productivity shocks.

The constraints to labor adjustment also imply a countercyclical labor wedge, as shown in Panel (g). Due to the presence of separation costs, in a recession firms reduce employment by less than the optimal amount. This generates a gap or wedge between the marginal productivity of labor and the marginal rate of substitution. In the standard neoclassical growth model this wedge is constant. Again, the economy with larger firing costs features a more volatile labor wedge.

Finally, panels (h) and (i) show the main components of aggregate demand: consumption and investment. Notice in this model that consumption falls almost as much as GDP in response to productivity shocks. This can be explained by the complementarity between consumption and labor supply induced by the GHH preferences. Similar to standard small open economy models, investment is highly responsive to productivity shocks. The calibration of the capital adjustment costs makes it possible to achieve a response consistent with the data.

\subsection{Business Cycle Statistics}

Starting from the baseline economy, we simulate the model for an alternative economy with the same stochastic processes for aggregate shocks but lower separation costs. The mid columns on Table 5 report the results of the experiment. The first and fourth columns

on this table report the corresponding business cycle statistics for Mexico and Canada, computed using HP-filtered data for the same time interval (1987:Q1 - 2007:Q3). 

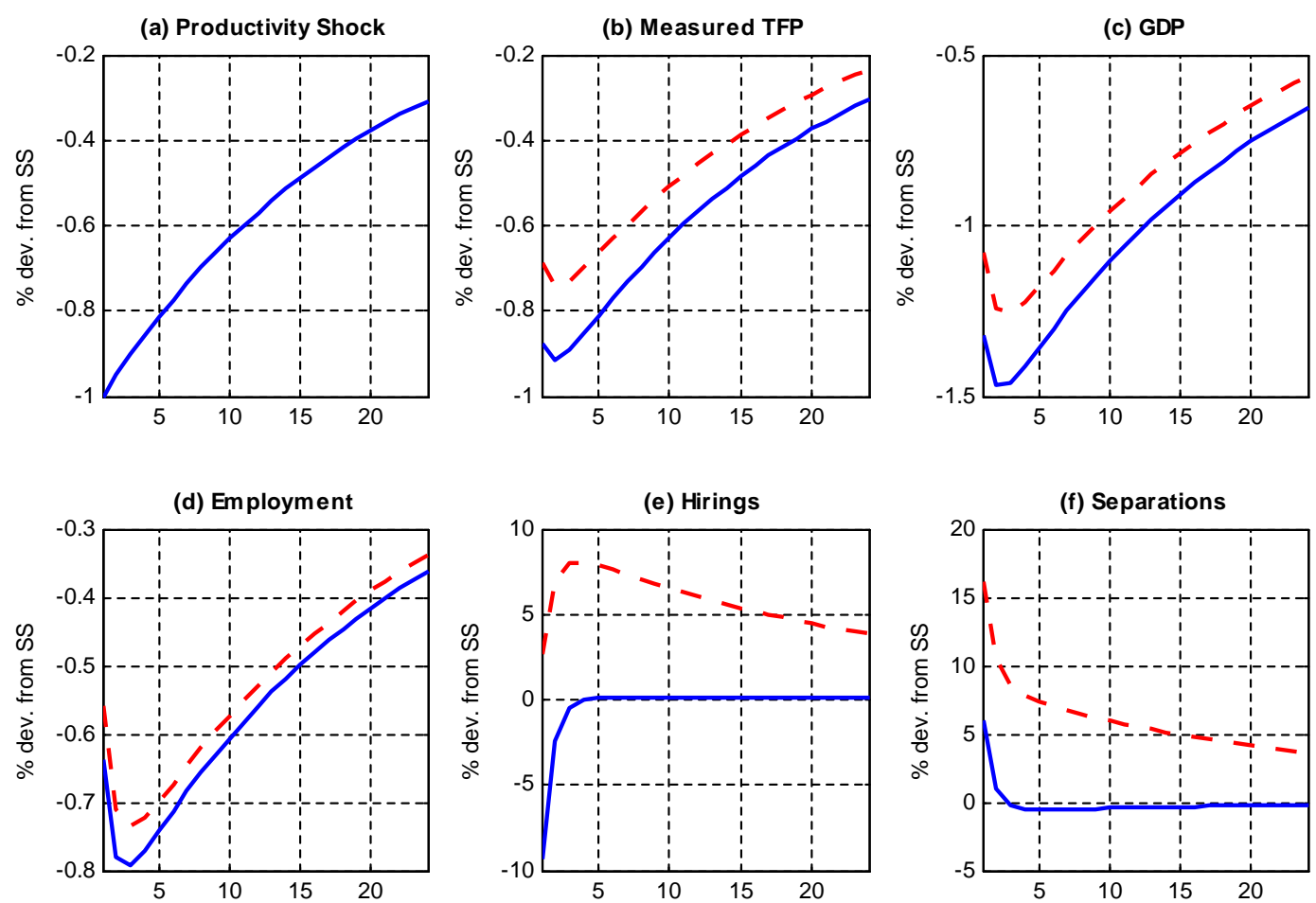

(g) Labor Wedge
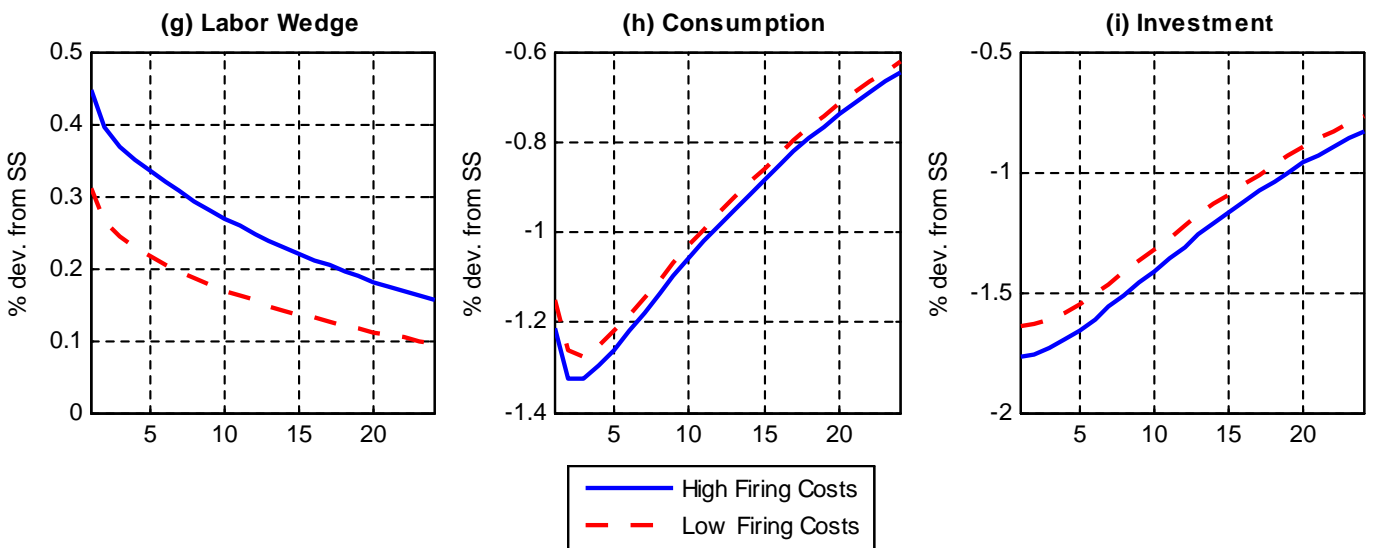

Figure 3: Impulse Response Function to an Exogenous Productivity Shock 


\begin{tabular}{|l|c|c|c|c|}
\hline & Data Mexico & Model: $\kappa \approx 4$ & Model: $\kappa \approx 1$ & Data Canada \\
\hline$\sigma(y)$ & 2.17 & 2.17 & 1.86 & 1.28 \\
$\sigma(t f p)$ & 1.98 & 1.36 & 1.08 & 0.86 \\
\hline$\sigma(l)$ & 1.15 & 1.16 & 1.16 & 0.86 \\
$\sigma(l) / \sigma(y)$ & 0.53 & 0.54 & 0.62 & 0.67 \\
$\sigma($ lwedge $)$ & 2.11 & 0.59 & 0.47 & 0.76 \\
Corr $($ lwedge, $y)$ & -0.73 & -0.96 & -0.71 & -0.42 \\
\hline$\sigma(c) / \sigma(y)$ & 1.15 & 1.46 & 1.72 & 0.86 \\
$\operatorname{Corr}(n x / y, y)$ & -0.78 & -0.14 & -0.12 & 0.03 \\
\hline
\end{tabular}

Table 5: Separation Costs and Business Cycle Statistics

Reducing the separation costs reduces the overall volatility of the economy. For the same process for the exogenous productivity component, the volatility of measured TFP decreases due to the selection mechanism: With lower separations costs, more inefficient matches are destroyed in recessions, increasing the average productivity of the remaining jobs. Therefore, output fluctuates less than in the baseline case. Notice that the effects are large. Reducing separation costs from the current level to a level more consistent with developed economies would reduce GDP volatility in Mexico by about 15 percent, closing one-third of the difference in GDP volatilities with Canada.

Separation costs have a negligible impact on employment volatility. The quantitative effects on job creation and job destruction almost cancel out. Therefore, reducing firing costs increases the relative volatility of labor with respect to GDP. This has an impact on the labor wedge defined in the previous section, which becomes less volatile and less correlated with output. We observe in the data that the volatility of the labor wedge in Canada is also lower than in Mexico and that the labor wedge is less countercyclical.

The experiment cannot explain the differences in the volatility of consumption and in the correlation of net exports with output between the two countries. Reducing firing costs actually makes consumption more volatile relative to output. This is because of the complementarity between consumption and labor supply induced by the GHH preference specification. While the absolute level of consumption and employment volatility do not change substantially with lower firing costs, output is less volatile due to the selection effect, increasing the ratio of volatilities. Notice, however, that in the experiment we are comparing economies subject to the same interest rate shocks. Table 4 suggests that if interest rate 
shocks were less volatile and less countercyclical in Canada the volatility of consumption would be significantly reduced.

In summary, starting from the baseline model calibrated to Mexico, reducing separation costs move qualitatively the business cycle moments in the direction of the Canadian economy. Quantitatively, the results are mixed, which is expected given that the only difference between Canada and Mexico that we are allowing in the model is labor regulation or separation costs.

\section{Separation Costs and the Great Recession of 2008}

In this final section we analyze through the lens of the model a particular episode, the Great Recession of 2008. In Mexico the downturn was particularly sharp, exhibiting a drop in GDP of about 9 percent (compared to trend) between 2008:Q1 and 2009:Q2. TFP was responsible for most of the drop in output, with a 8.5 percent fall below trend. Employment felt much less, about 3.5 percent below trend, suggesting a mild adjustment of the labor market.

\subsection{Accounting for the Mexican Recession of 2008}

We use the baseline model calibrated in the previous section to perform an accounting exercise for the period between 2007:Q4 and 2010:Q2. We know the observed sequence of interest rates for Mexico in international markets for this period, using again the EMBI spread as a proxy for the country risk premium. We choose the sequence of the exogenous aggregate productivity shock in order to reproduce the observed evolution of GDP. Given these two sequences of realizations of the exogenous shocks, we compute the corresponding time series for employment, consumption, investment, and so on, generated by the optimal decision rules of the model. Figure 4 reports the results of the exercise and compares it with the Mexican data ${ }^{13}$.

By construction, the model generates the same fall in GDP as the one observed in

\footnotetext{
${ }^{13}$ We first HP-filtered the time series from the data using the whole 1987:Q1 to 2010:Q2 sample. The plotted sequences for the interval 2007:Q4 to 2010:Q2 should then be interpreted as deviations from a long run trend. Notice that the calibration of the model discussed in Section 3 only used Mexican data from 1987:Q1 to 2007:Q3, making the results this experiment an out-of-sample prediction of the model.
} 

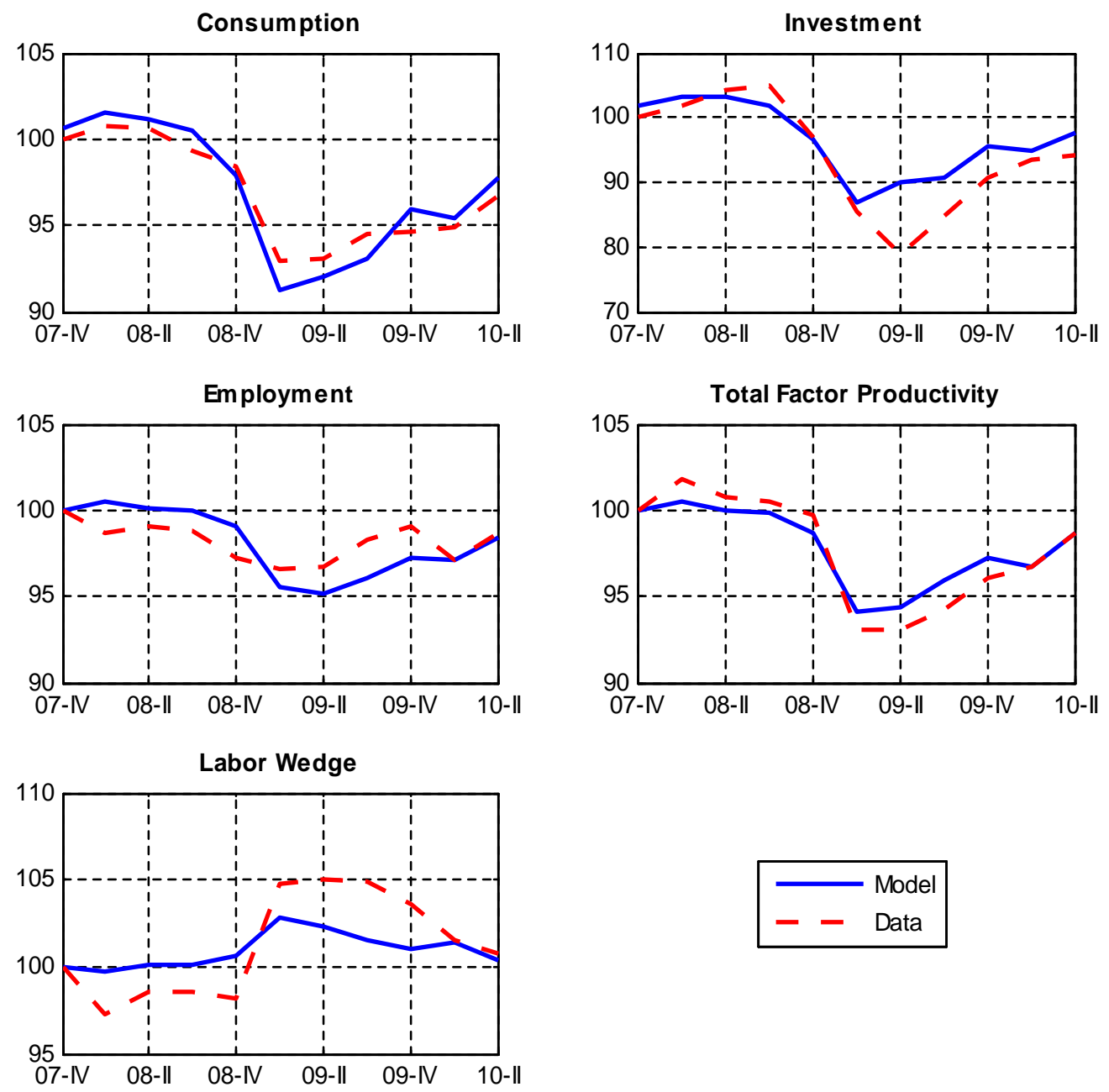

Figure 4: Accounting for the Mexican Recession of 2008: Model and Data Comparison 
Mexico. More interestingly, the model is also consistent with the observed fall in consumption, investment and employment. Notice, however, that the model overpredicts the size of the fall in employment, which is about 5 percent in the model compared with 3.5 percent in the data. The labor market frictions in the model generate a decrease in measured TFP and increase in the labor wedge which are also observed in the data. Quantitatively, the model accounts for about two-thirds of the increase in the labor wedge in Mexico. We will see next that separation costs are key to account for the increase in the degree of inefficiency in the labor market.

\subsection{A Counterfactual Experiment with Low Separation Costs}

We now perform the following counterfactual experiment: How different would have been the 2008 recession in an economy facing the same exogenous shocks as Mexico but with lower separation costs? The experiment implies a recalibration of the steady state parameters in order to be consistent with the same initial steady state as in the baseline economy. We also reduce the firing cost to one-fourth its level in the baseline economy. As discussed before, this is a reasonable value for separation costs in Canada, relative to its calibrated value for Mexico. Figure 5 reports the results of the counterfactual experiment.

The economy with lower firing costs suffers a smaller recession, 7.6 percent below trend between 2008:Q1 and 2009:Q2 compared with 8.9 percent in the baseline economy with high firing costs. According to the experiment, the high level of separation costs in Mexico adds 1.3 percentage points to the fall in GDP during the 2008 crisis. This is entirely a productivity effect due to the selection mechanism in the model. For the same sequence of exogenous aggregate productivity, measured TFP falls more in a recession with high firing cost because these costs allow more inefficient jobs to stay active.

As discussed in the previous sections, having low separation costs does not imply a bigger fall in employment. Indeed, employment falls by almost the same amount in both economies, about 5 percent below trend. This is not to say that firing costs do not have important effects on labor flows. Separations increase sharply during the recession, and they increase about 2.5 times more in the economy with low separation costs. This reinforces the idea that separation costs have an impact not only on job destruction, but also on job 

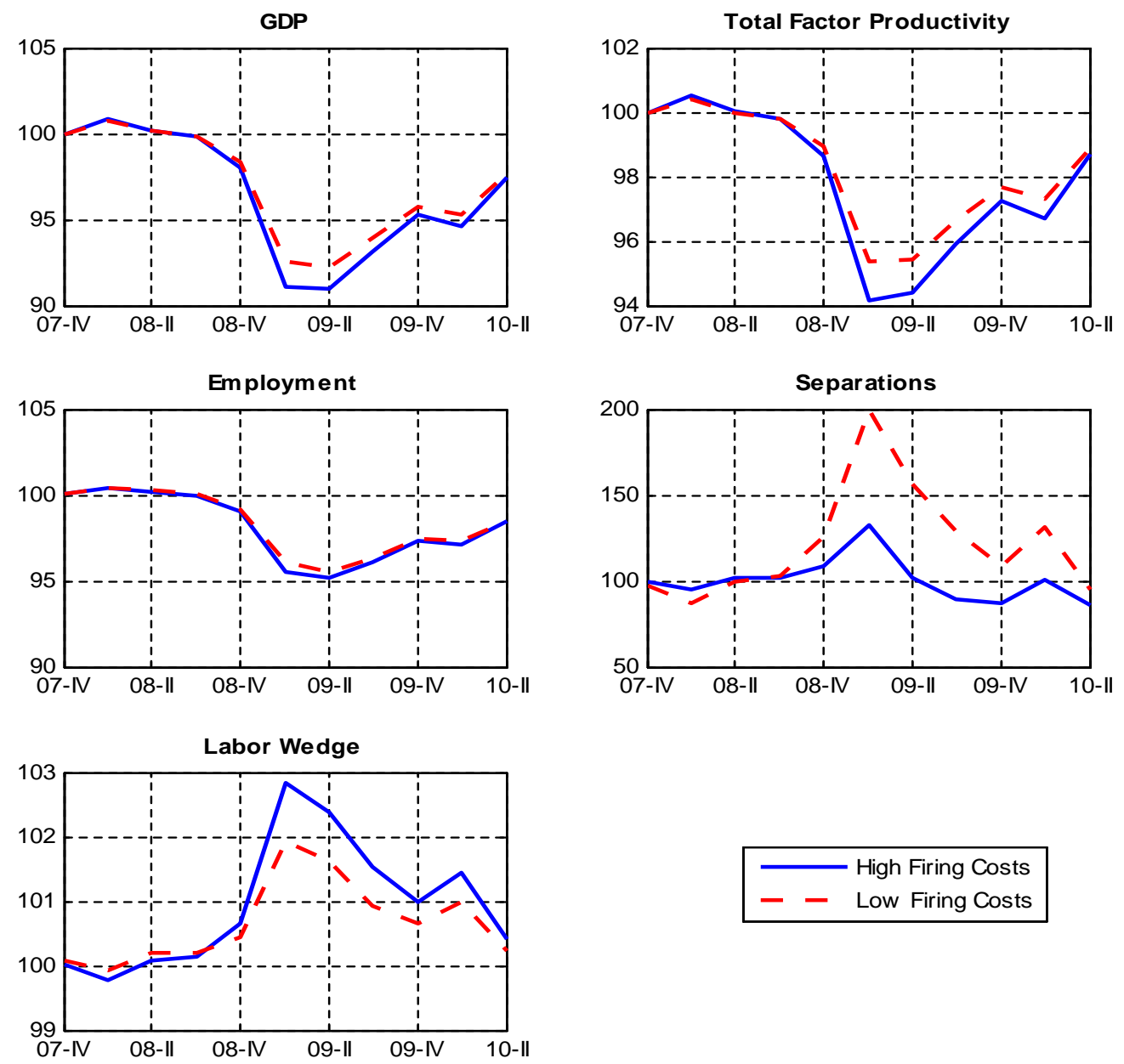

Figure 5: Counterfactual Experiment: The 2008 Mexican Crisis with Lower Separation Costs 
creation. In our experiment, the net effect on employment is negligible. Of course, relative to GDP employment falls more in the economy with low firing costs, this is why the increase in the labor wedge is also smaller.

According to our experiment, facing similar shocks, an economy with lower firing costs would have experienced a smaller drop in GDP and measured TFP, a similar drop in employment but a smaller increase in the labor wedge. Figure 6 compares the impact of the Great Recession of 2008 in Mexico and Canada using detrended (HP-filtered) data. Of course it is hard to argue that the shocks were indeed similar in both countries. Still, it is remarkable that the predictions of the model are broadly consistent with the experience of these two economies.

\subsection{Sensitivity Analysis}

Finally, we check the sensitivity of our results with respect to four parameters, which values were taken from the literature instead of being calibrated within our exercise. These are the labor supply elasticity $(1 / \nu)$, the curvature of the Pareto distribution $\left(\sigma_{\omega}\right)$ for idiosyncratic productivity shocks, the elasticity of the matching function with respect to unemployment $(\theta)$ and the capital share in the aggregate production function $(\alpha)$. For this, we repeat the 2008 crisis experiment with high and low firing costs under the alternative sets of parameters. In order to summarize the information, in Table 5 we compute the contribution of separation costs to the fall in GDP, employment and TFP in Mexico during the Great Recession under the baseline model and for the alternative sets of parameters.

Lowering the labor supply elasticity slightly reduces the contribution of separation costs to the fall in GDP, from 1.3 percentage points in the baseline to 1.2 percentage points under a very low elasticity of 0.1 , which lies below the most conservative micro estimates. The impact of firing costs on employment is, however, significantly reduced as this elasticity shrinks and labor supply becomes less sensitive to changes in productivity. Notice, though, that the impact of firing costs on employment was already small in the baseline by their countervailing effect on job creation and job destruction. The contribution of separation costs to the fall in measured TFP is, therefore, larger under the smaller labor supply elasticity. None of these results change the main message of the exercise. 

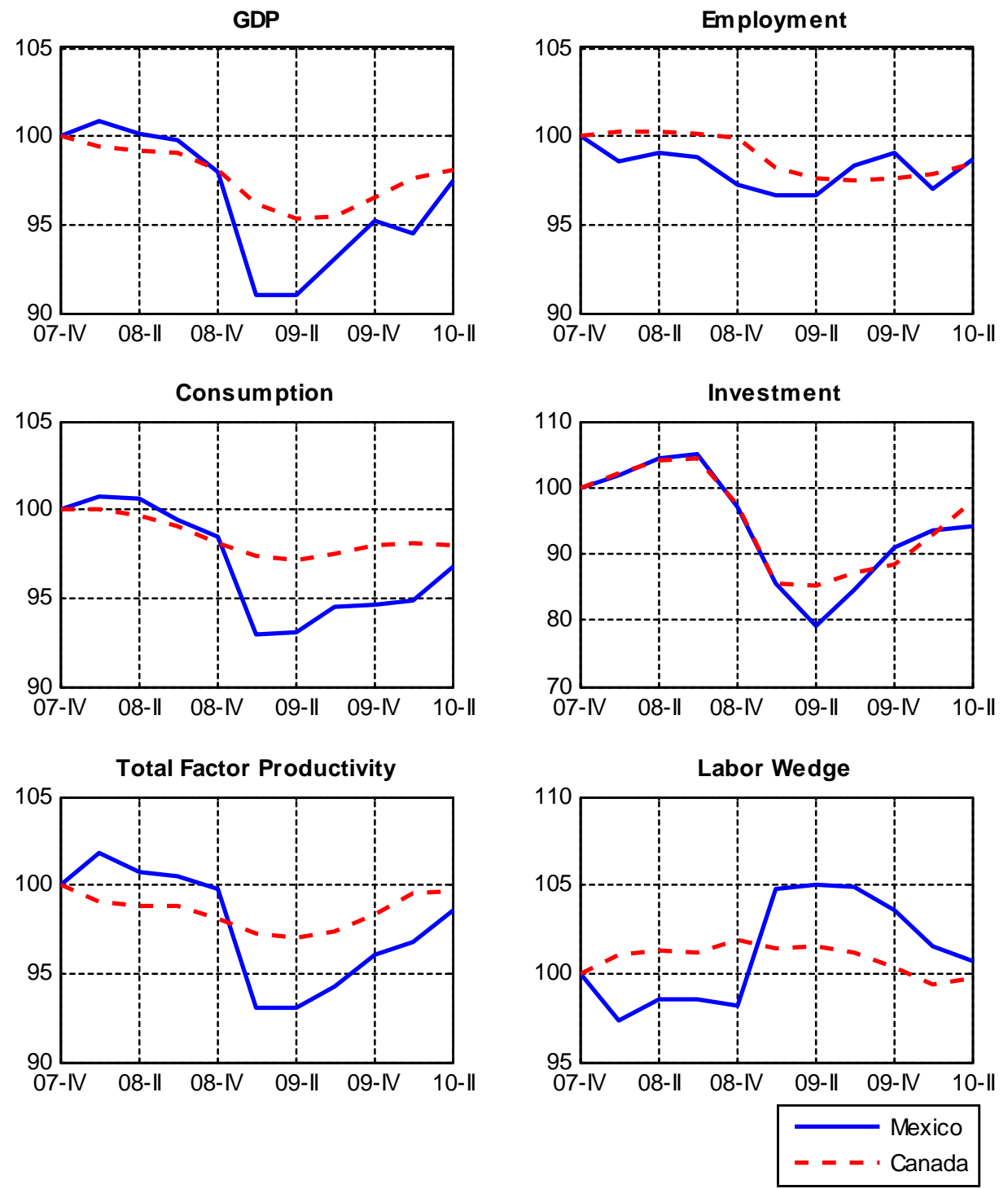

Figure 6: The Great Recession of 2008 in Mexico and Canada: HP Filtered Data 


\begin{tabular}{|l|c|cc|cc|}
\hline & Baseline model & \multicolumn{2}{|c|}{ Labor Supply Elasticity } & \multicolumn{2}{|c|}{ Curvature Pareto } \\
& $\left(1 / \nu \approx 2.6, \sigma_{\omega}=1.5\right)$ & $1 / \nu=1$ & $1 / \nu=0.1$ & $\sigma_{\omega}=1.1$ & $\sigma_{\omega}=2$ \\
\hline$y$ & 1.32 & 1.25 & 1.22 & 1.73 & 1.05 \\
$l$ & 0.37 & 0.15 & 0.01 & -0.09 & 0.44 \\
$t f p$ & 1.06 & 1.14 & 1.21 & 1.78 & 0.74 \\
\hline & Baseline model & \multicolumn{2}{|c|}{ Matching Elasticity } & \multicolumn{2}{|c|}{ Capital Share } \\
& $(\theta=0.4, \alpha=0.3)$ & $\theta=0.2$ & $\theta=0.6$ & $\alpha=0.25$ & $\alpha=0.4$ \\
\hline$y$ & 1.32 & 1.70 & 0.59 & 1.44 & 1.10 \\
$l$ & 0.37 & 0.59 & 0.02 & 0.43 & 0.25 \\
$t f p$ & 1.06 & 1.27 & 0.59 & 1.11 & 0.94 \\
\hline
\end{tabular}

Note: This table shows the contribution in percentage points of separation costs to the fall of each variable during the 2008 recession in Mexico under different parameter sets. For example, the high level of firing costs in Mexico add 1.32 percentage points to the fall in GDP obtained under the baseline economy with low firing costs.

Table 6: Sensitivity Analysis for the Mexican 2008 Great Recession Episode

Our results are more sensitive to the curvature of the Pareto distribution for idiosyncratic productivity shocks. Decreasing this curvature from 1.5 to 1.1, which implies a flatter slope in the cumulative distribution of productivity shocks, significantly increases the contribution of separation costs to both GDP and measured TFP contractions. The intuition is that an increase in the threshold productivity $\left(\hat{\omega}_{t}\right)$ during the recession implies with low curvature a smaller increase in the number of matches closed by the planner, hence a larger fall in TFP due to the (lack of) selection effect. Indeed, in this case the impact of firing costs on the fall of employment is close to zero. With a high curvature of 2 the effects are reversed and separation costs contribute more to the fall of employment and less to the output and TFP contractions than in the baseline case.

The elasticity of the matching function with respect to unemployment also has a strong impact on our quantitative results. Decreasing this elasticity increases the response of all three variables (GDP, employment, and measured TFP) to separation costs during a recession. This highlights the feedback in the model from labor market tightness to hiring decisions. The lower the impact of unemployment in the probability of filling a vacancy, the lower the incentives for the planner to hire new workers in a recession, hence the larger the fall in aggregate employment and its cleansing effect on productivity.

Finally, a higher capital share, implying a smaller elasticity of output with respect to 
labor, makes all three variables less sensitive with respect to firing costs. The quantitative differences are, however, very small.

\section{Conclusions}

Labor market outcomes impose some discipline to small open economy models of business cycles. They also provide new insights in understanding the differences across countries. We have explored a particular story. High separation costs in emerging economies dampen the selection effect and its cleansing impact during recessions, making these economies more volatile in terms of output and measured TFP. According to our analysis, this mechanism seems to be quantitatively important in explaining business cycle differences between emerging economies and more developed, less restricted, countries.

Even though we have used Mexico and Canada as examples to illustrate our story, we think that the model can be used in more general cases. One interesting application is to compare developed economies with different levels of employment protection. Ohanian (2010) shows that the Great Recession of 2008 had a very different impact in the U.S. and Europe, with employment falling more in the former and measured TFP decreasing more in the latter. This could be rationalized in the context of our model assuming lower separation costs in the US economy relative to Europe. Another application is to evaluate the impact of the informal labor markets on TFP at business cycles frequencies. Our model could be extended to include an informal sector which operates under no dismissal costs. The reallocation of labor across sectors could also explain the volatility of TFP observed in emerging economies. ${ }^{14}$

Most of the previous literature explains differences in business cycles across countries using different shocks, in particular different stochastic processes for exogenous productivity, or different preferences. We believe that taking into account institutional features, which differ across countries and propagate shocks differently, provides more structure to identify the sources of business cycles and to conduct policy analysis. Our results point out to labor

\footnotetext{
${ }^{14}$ Loayza and Rigolini (2006) find that informality in labor markets tends to be countercyclical. To the extent that the informal sector has lower productivity than the formal sector, this reallocation will increase aggregate TFP volatility.
} 
market frictions as a potential explanation for these differences. 


\section{References}

[1] Aguiar, Mark and Gita Gopinath (2007), "Emerging Market Business Cycles: The Cycle is the Trend," Journal of Political Economy, Vol. 115(1), pp. 69-102.

[2] Andolfatto, David (1996), "Business Cycles and Labor-Market Search," American Economic Review, Vol. 86(1), pp. 112-132.

[3] Benhabib, Jess R. , R. Rogerson, and R. Wright (1991), "Homework in Macroeconomics: Household Production and Aggregate Fluctuations," Journal of Political Economy, Vol. 99, pp. 1166-1187.

[4] Blanchard, Olivier and Charles Kahn (1980), "The Solution of Linear Difference Models under Rational Expectations," Econometrica, Vol. 48, pp. 1305-1311.

[5] Blanchard, Olivier and Peter Diamond (1989), "The Beveridge Curve," Brookings Papers on Economic Activity, pp. 1-76.

[6] Bosch, Mariano, and William Maloney (2007), "Gross Worker Flows in the Presence of Informal Labor Markets: Evidence from Mexico, 1987-2002," IZA Discussion Paper No. 2864.

[7] Bosch, Mariano and William Maloney (2009), "Cyclical Movements in Unemployment and Informality in Developing Countries," Policy Research Working Paper Series 4648, The World Bank.

[8] Boz, Emine, Bora Durdu, and Nan Li (2009), "Labor Market Search in Emerging Economies," mimeo.

[9] Chari, V.V., Patrick Kehoe, and Ellen McGrattan (2007), "Business Cycle Accounting," Econometrica, Vol. 75, pp. 781-836.

[10] Christiano, L., M. Trabandt, and K. Walentin (2010), "Introducing Financial Frictions and Unemployment into a Small Open Economy Model," Sveriges Riksbank, Working Paper Series No. 214. 
[11] Den Haan, Wouter J., G. Ramey, and J. Watson (2000), "Job Destruction and Propagation of Shocks," American Economic Review, Vol. 90, pp. 482-498

[12] Fernandez, Andrés and Felipe Meza (2011), "Sudden Stops, Consumption and Labor: a Test for Emerging Market Business Cycle Models," mimeo.

[13] Greenwood, Jeremy, Zvi Hercowitz, and Gregory Huffman (1988), "Investment, Capacity Utilization, and the Real Business Cycle," American Economic Review, Vol. 78(3), pp. $402-17$.

[14] Heckman, J. and C. Pages (2000), "The Cost of Job Security Regulation: Evidence from Latin American Labor Markets," Inter-American Development Bank Working Paper 430.

[15] International Labor Organization (2009). "Key Indicators of the Labour Market (KILM)." available at http://kilm.ilo.org/KILMnetBeta/default2.asp.

[16] Kaplan, David, Gabriel Martinez, and Raymond Robertson (2005), "Worker and Job Flows in Mexico," mimeo.

[17] Lagos, Ricardo (2006), "A Model of TFP," Review of Economic Studies, Vol. 73, pp. 983-1007.

[18] Lama, Ruy (2011), "Accounting for Output Drops in Latin America," Review of Economic Dynamics, Vol. 14, pp. 295-316.

[19] Loayza, Norman and Jamele Rigolini (2006), "Informality Trends and Cycles," World Bank Policy Research Working Paper No. 4078.

[20] Mendoza, Enrique (2010), "Sudden Stops, Financial Crises, and Leverage," American Economic Review, Vol 100, pp. 1941-66.

[21] Merz, Monica (1995), "Search in the Labor Market and the Real Business Cycle," Journal of Monetary Economics, Vol. 36, pp. 269-300.

[22] Mortensen, Dale and Christopher Pissarides (1994), "Job Creation and Job Destruction in the Theory of Unemployment," Review of Economic Studies, Vol. 61, pp. 397-415. 
[23] Neumeyer, Pablo and Fabrizio Perri (2005), "Business Cycles in Emerging Economies: the Role of Interest Rates," Journal of Monetary Economics, Vol. 52, pp. 345-380.

[24] Ohanian, Lee (2010), "The Economic Crisis from a Neoclassical Perspective," Journal of Economic Perspectives, Vol. 24, pp. 45-66.

[25] Pratap, Sangeeta and Erwin Quintin (2010), "Financial Crises and Labor Market Turbulence," mimeo.

[26] Rogerson, Richard and Johanna Wallenius (2007), "Micro and Macro Elasticities in a Life Cycle Model with Taxes," NBER Working Paper 13017.

[27] Schmitt-Grohé, Stephanie (1998), "The international transmission of economic fluctuations:: Effects of U.S. business cycles on the Canadian economy," Journal of International Economics, 44, pp. 257-287.

[28] Schmitt-Grohé, Stephanie and Martin Uribe (2003), "Closing Small Open Economy Models," Journal of International Economics, 61, pp. 163-185.

[29] Schmitt-Grohé, Stephanie and Martin Uribe (2004), "Solving Dynamic General Equilibrium Models Using a Second-Order Approximation to the Policy Function," Journal of Economic Dynamics and Control, Vol. 28, pp. 755-775.

[30] Shimer, Robert (2005), "The Cyclical Behavior of Equilibrium Unemployment and Vacancies ," American Economic Review, Vol. 95, pp. 25-49.

[31] Shimer, Robert (2009), "Convergence in Macroeconomics: The Labor Wedge," American Economic Journal: Macroeconomics, Vol. 1, pp. 280-297.

[32] Veracierto, Marcelo (2007), "Establishments Dynamics and Matching Frictions in Classical Competitive Equilibrium," Working Paper Series WP-07-16, Federal Reserve Bank of Chicago.

[33] World Bank (2010) Doing Business in 2011: Making a Difference for Entrepreneurs, Washington, World Bank. 
[34] Zhang, Min (2008) "Cyclical Behavior of Unemployment and Job Vacancies: A Comparison between Canada and the United States," The B.E. Journal of Macroeconomics: Vol. 8: Iss. 1 (Topics), Article 27. 


\section{A Technical Appendix}

\section{A.1 Solving the Planner's Problem}

Given initial conditions $B_{0}$ and $L_{-1}$, and the stochastic process for aggregate shocks, the social planner chooses contingent plans for aggregate variables $\left\{C_{t}, I_{t}, N X_{t}, K_{t+1}, B_{t+1}, M_{t}\right.$, $\left.U_{t}, L_{t}, V_{t}, \hat{\omega}_{t}\right\}_{t=0}^{\infty}$ in order to solve

$$
\begin{aligned}
& \max \quad E_{0} \sum_{t=0}^{\infty} \beta^{t} \frac{\left[C_{t}-\varphi \frac{L_{t}^{1+\nu}}{1+\nu}\right]^{1-\sigma}}{1-\sigma} \\
& \text { s.to. } \quad C_{t}+I_{t}+N X_{t}+\eta V_{t}+\kappa G\left(\hat{\omega}_{t}\right)\left[L_{t-1}+D\left(U_{t}\right)^{\theta}\left(V_{t}\right)^{1-\theta}\right]=A_{t}\left(K_{t}\right)^{\alpha}\left(M_{t}\right)^{1-\alpha}\left(\beta^{t} \lambda_{t}^{C}\right) \\
& K_{t+1}=(1-\delta) K_{t}+I_{t}-\frac{\vartheta}{2}\left(\frac{I_{t}}{K_{t}}-\delta\right)^{2} K_{t} \quad\left(\beta^{t} \lambda_{t}^{K}\right) \\
& M_{t}=\left[\frac{\Gamma\left(\hat{\omega}_{t}\right)}{1-G\left(\hat{\omega}_{t}\right)}\right] L_{t} \\
& B_{t+1}=\left(1+r_{t}^{*}\right) B_{t}-N X_{t} \\
& L_{t}+U_{t}=\bar{L} \\
& L_{t}=\left(1-G\left(\hat{\omega}_{t}\right)\right)\left[L_{t-1}+D\left(U_{t}\right)^{\theta}\left(V_{t}\right)^{1-\theta}\right]
\end{aligned}
$$

The Lagrange multipliers are in parenthesis. As usual, we factor these multipliers by $\beta^{t}$ to make them stationary.

\section{A.1.1 First Order Conditions}

$\frac{\partial}{\partial C_{t}}:$

$$
\lambda_{t}^{C}=\left[C_{t}-\varphi \frac{L_{t}^{1+\nu}}{1+\nu}\right]^{-\sigma}
$$


$\frac{\partial}{\partial I_{t}}:$

$$
\lambda_{t}^{C}=\lambda^{K}\left(1-\vartheta\left(\frac{I_{t}}{K_{t}}-\delta\right)\right)
$$

$\frac{\partial}{\partial K_{t+1}}:$

$$
\lambda_{t+1}^{C} r_{t+1}=\lambda_{t}^{K}-\lambda_{t+1}^{K}\left(1-\delta+\vartheta\left(\frac{I_{t+1}}{K_{t+1}}-\delta\right) \frac{I_{t+1}}{K_{t+1}}-\frac{\vartheta}{2}\left(\frac{I_{t+1}}{K_{t+1}}-\delta\right)^{2}\right)
$$

with

$$
r_{t} \equiv \alpha A_{t}\left(\frac{K_{t}}{M_{t}}\right)^{\alpha-1}
$$

$\frac{\partial}{\partial B_{t+1}}:$

$$
\lambda_{t}^{B}=\beta E_{t} \lambda_{t+1}^{B}\left(1+r_{t+1}^{*}\right)
$$

$\frac{\partial}{\partial N X_{t}}:$

$$
\lambda_{t}^{C}=-\lambda_{t}^{B}
$$

$\frac{\partial}{\partial M_{t}}:$

$$
\lambda_{t}^{M}=\lambda_{t}^{C} p_{t}^{M}
$$

with

$$
p_{t}^{M} \equiv(1-\alpha) A_{t}\left(\frac{K_{t}}{M_{t}}\right)^{\alpha}
$$

$\frac{\partial}{\partial U_{t}}:$

$$
\lambda_{t}^{U}=\phi\left(\frac{V_{t}}{U_{t}}\right)^{1-\phi}\left[\lambda_{t}^{L}\left(1-G\left(\hat{\omega}_{t}\right)\right)-\lambda_{t}^{C} \kappa G\left(\hat{\omega}_{t}\right)\right]
$$

$\frac{\partial}{\partial L_{t}}:$

$$
\lambda_{t}^{M} \frac{\Gamma\left(\hat{\omega}_{t}\right)}{1-G\left(\hat{\omega}_{t}\right)}=\lambda_{t}^{C} \varphi L_{t}^{\nu}+\lambda_{t}^{U}+\lambda_{t}^{L}-\beta E_{t}\left\{\lambda_{t+1}^{L}\left(1-G\left(\hat{\omega}_{t+1}\right)\right)-\lambda_{t+1}^{C} \kappa G\left(\hat{\omega}_{t+1}\right)\right\}
$$

$\frac{\partial}{\partial V_{t}}:$

$$
\lambda_{t}^{C} \eta=(1-\phi)\left(\frac{V_{t}}{U_{t}}\right)^{-\phi}\left[\lambda_{t}^{L}\left(1-G\left(\hat{\omega}_{t}\right)\right)-\lambda_{t}^{C} \kappa G\left(\hat{\omega}_{t}\right)\right]
$$

$\frac{\partial}{\partial \hat{\omega}_{t}}:$

$$
-\lambda_{t}^{C} \kappa G^{\prime}\left(\hat{\omega}_{t}\right) L_{t-1}+\lambda_{t}^{M}\left[\frac{\Gamma^{\prime}\left(\hat{\omega}_{t}\right)}{1-G\left(\hat{\omega}_{t}\right)}+\frac{\Gamma\left(\hat{\omega}_{t}\right) G^{\prime}\left(\hat{\omega}_{t}\right)}{\left(1-G\left(\hat{\omega}_{t}\right)\right)^{2}}\right] L_{t}
$$




$$
-G^{\prime}\left(\hat{\omega}_{t}\right) \lambda_{t}^{L}\left[L_{t-1}+D\left(U_{t}\right)^{\theta}\left(V_{t}\right)^{1-\theta}\right]=0
$$

\section{A.1.2 Optimal Separation Rule}

We can rewrite the first order condition with respect to $L_{t}$ :

$$
\frac{\lambda_{t}^{L}}{\lambda_{t}^{C}}=p_{t}^{M} \frac{\Gamma\left(\hat{\omega}_{t}\right)}{1-G\left(\hat{\omega}_{t}\right)}-\varphi L_{t}^{\nu}-\lambda_{t}^{U} / \lambda_{t}^{C}+\beta E_{t}\left(\lambda_{t+1}^{C} / \lambda_{t}^{C}\right)\left\{\left(1-G\left(\hat{\omega}_{t+1}\right)\right) \frac{\lambda_{t+1}^{L}}{\lambda_{t+1}^{C}}-\kappa G\left(\hat{\omega}_{t+1}\right)\right\} .
$$

This defines recursively the value of the average worker as the expected present value of the output generated by the job net of the shadow price of an unmatched worker.

Also, we can write the first order condition with respect to $\hat{\omega}_{t}$ as:

$$
\frac{\lambda_{t}^{L}}{\lambda_{t}^{C}}-p_{t}^{M}\left[\frac{\Gamma^{\prime}\left(\hat{\omega}_{t}\right) / G^{\prime}\left(\hat{\omega}_{t}\right)}{\left(1-G\left(\hat{\omega}_{t}\right)\right)}+\frac{\Gamma\left(\hat{\omega}_{t}\right)}{\left(1-G\left(\hat{\omega}_{t}\right)\right)^{2}}\right] \frac{L_{t}}{L_{t-1}}=-\kappa
$$

or, using the law of motion for labor,

$$
\frac{\lambda_{t}^{L}}{\lambda_{t}^{C}}-p_{t}^{M}\left[\frac{\Gamma^{\prime}\left(\hat{\omega}_{t}\right)}{G^{\prime}\left(\hat{\omega}_{t}\right)}+\frac{\Gamma\left(\hat{\omega}_{t}\right)}{1-G\left(\hat{\omega}_{t}\right)}\right]=-\kappa
$$

Combining (13) and (14), we obtain

$$
p_{t}^{M}\left[\frac{-\Gamma^{\prime}\left(\hat{\omega}_{t}\right)}{G^{\prime}\left(\hat{\omega}_{t}\right)}\right]-\varphi L_{t}^{\nu}-\lambda_{t}^{U} / \lambda_{t}^{C}+\beta E_{t}\left(\lambda_{t+1}^{C} / \lambda_{t}^{C}\right)\left\{\left(1-G\left(\hat{\omega}_{t+1}\right)\right) \frac{\lambda_{t+1}^{L}}{\lambda_{t+1}^{C}}-\kappa G\left(\hat{\omega}_{t+1}\right)\right\}=-\kappa .
$$

Finally, using the definition $\Gamma(x) \equiv \int_{\omega \geq x} \omega d G(\omega)$ and Leibniz rule, $\Gamma^{\prime}(x)=-x G^{\prime}(x)$ and

$$
p_{t}^{M} \hat{\omega}_{t}-\varphi L_{t}^{\nu}-\lambda_{t}^{U} / \lambda_{t}^{C}+\beta E_{t}\left(\lambda_{t+1}^{C} / \lambda_{t}^{C}\right)\left\{\left(1-G\left(\hat{\omega}_{t+1}\right)\right) \frac{\lambda_{t+1}^{L}}{\lambda_{t+1}^{C}}-\kappa G\left(\hat{\omega}_{t+1}\right)\right\}=-\kappa .
$$

Equation (15) describes the optimal separation rule: The planner will choose a labor efficiency threshold so that the marginal worker has a social value, measured again as the expected present value of the output generated net of the shadow price of an unmatched worker, equal to the cost of destroying the job.

So far, our analysis assumes that the optimal separation rule implies a threshold levels 
$\hat{\omega}_{t}$ such that the planner destroys jobs with labor efficiency below it. To complete the characterization of the efficient allocations, we have to show that this is indeed the case. For this, we use the previous concept of the social value of a standing job, that we denote $\pi_{t}(\omega)$, as the expected present value of the output generated by the job net of the shadow price of an unmatched worker:

$$
\pi_{t}(\omega)=p_{t}^{M} \omega-\varphi L_{t}^{\nu}-\lambda_{t}^{U} / \lambda_{t}^{C}+\beta E_{t}\left(\lambda_{t+1}^{C} / \lambda_{t}^{C}\right) \int \max \left\{\pi_{t+1}\left(\omega^{\prime}\right),-\kappa\right\} d G\left(\omega^{\prime}\right) .
$$

The planner destroys jobs such that $\pi_{t}(\omega)<-\kappa$. As $\pi_{t}$ is monotonically increasing in $\omega$, then the optimal rule is to shred jobs with $\omega<\hat{\omega}_{t}$, where $\hat{\omega}_{t}$ is an endogenous, sector specific, and state dependent threshold level satisfying $\pi_{t}\left(\hat{\omega}_{t}\right)=-\kappa$. Notice that this last equality corresponds exactly with equation (15) characterizing the optimal separation rule. 